\title{
Gastroparesis and Functional Dyspepsia: A Blurring Distinction of Pathophysiology and Treatment
}

\author{
Beom Jin Kim ${ }^{1,2}$ and Braden $\mathrm{Kuo}^{2 *}$ \\ ${ }^{I}$ Department of Internal Medicine, Chung-Ang University College of Medicine, Seoul, Korea; and ${ }^{2}$ Gastrointestinal Unit, Center of Neuroenteric \\ Health, Massachusetts General Hospital, Harvard Medical School, Boston, USA
}

\begin{abstract}
Gastroparesis and functional dyspepsia are 2 of the most common gastric neuromuscular disorders. These disorders are usually confused, having both similarities and differences. The pathophysiology of these disorders involves abnormal gastric motility, visceral hypersensitivity, mucosal inflammation, and various cellular changes. Both disorders have similar symptoms such as epigastric pain or discomfort, early satiety, and bloating. If patients suspected of having either gastroparesis or functional dyspepsia present with upper gastrointestinal symptoms, they should undergo upper endoscopy to exclude an alternative organic cause. Although the gastric emptying rate is frequently assessed during the clinical workup of patients with gastroparesis or functional dyspepsia, the correlation between gastric emptying and the symptoms is generally poor. Once the diagnosis of gastroparesis or functional dyspepsia is made, treatment should focus on the predominant symptom. Recently, various treatment modalities have been developed and validated. Prokinetic agents are generally used as treatment for both gastroparesis and functional dyspepsia. Acid-suppressive therapy, Helicobacter pylori eradication, and use of drugs that enhance gastric accommodation are employed for functional dyspepsia. Psychoactive drugs are also effective in symptom control. For gastroparesis, antiemetic agents, ghrelin receptor agonists, and serotonergic agents are used aside from prokinetic agents. Acupuncture and gastric electrical stimulation can be attempted. In severe cases, endoscopic and surgical interventions are considered for symptom control.
\end{abstract}

(J Neurogastroenterol Motil 2019;25:27-35)

Key Words

Dyspepsia; Gastroparesis; Pathophysiology; Therapeutics

\section{Introduction}

The most common sensorimotor disorders involving the upper gastrointestinal tract are gastroparesis (GP) and functional dyspepsia (FD). ${ }^{1}$ Disruption of the gastric sensorimotor function is the main factor in the pathogenesis of upper gastrointestinal symptoms. ${ }^{2}$ Recent studies have focused on the relationship between patho- physiological mechanisms and symptom generation, which include delayed gastric emptying, gastric hypersensitivity, and impaired accommodation. ${ }^{2}$ GP epidemiologically and pathophysiologically overlaps with $\mathrm{FD}$, with numerous patients being mistakenly labeled as having GP.

Despite considerable progress in the understanding of the enteric neuromuscular dysfunctions and the gastric sensorimotor dysfunctions associated with these diseases, more research is re-

Received: September 28, 2018 Revised: October 26, 2018 Accepted: October 30, 2018

(c) This is an Open Access article distributed under the terms of the Creative Commons Attribution Non-Commercial License (http://creativecommons. org/licenses/by-nc/4.0) which permits unrestricted non-commercial use, distribution, and reproduction in any medium, provided the original work is properly cited.

*Correspondence: Braden Kuo, MD, PhD

Gastrointestinal Unit, Center of Neuroenteric Health, 165 Cambridge Street 9th Floor, Boston, MA 02114, USA

Tel: +1-617-724-6038, Fax: +1-617-726-2047, E-mail: BKUO@mgh.harvard.edu 
quired to better understand the etiology and relationship between neuromuscular dysfunctions of the enteric tract and underlying pathophysiology, and symptoms. ${ }^{3}$

As the distinction between GP and FD is vague by their clinical features such as delayed gastric emptying, ${ }^{3}$ it is necessary to understand the abnormalities of the sensorimotor function to differentiate these 2 diseases. This review was intended to emphasize the similarities and differences in terms of the pathophysiology, symptom, diagnosis, and treatment between GP and FD.

\section{Definition}

\section{Gastroparesis}

GP is a syndrome characterized by delayed gastric emptying in the absence of mechanical obstruction. ${ }^{4,5}$

\section{Functional Dyspepsia}

FD is defined by the Rome IV diagnostic criteria as the presence of one or more of the following symptoms: bothersome postprandial fullness, bothersome early satiation, bothersome epigastric pain, or bothersome epigastric burning, and no evidence of structural disease (including upper endoscopic findings) to explain the symptoms. ${ }^{6}$ FD can be subclassified into 2 subgroups. Postprandial distress syndrome [PDS] is characterized by meal-induced dyspeptic symptoms, and epigastric pain syndrome [EPS] is expressed as epigastric pain or burning that is not exclusively postprandial. ${ }^{7}$ PDS and EPS subgroups have overlapping symptoms and PDS is more difficult to distinguish from GP than EPS, Although there are differences according to symptom severity, PDS is more difficult to distinguish from GP than EPS. ${ }^{8,9}$

\section{Etiology}

\section{Gastroparesis}

The etiology of GP is multifactorial, with the key triggers being diabetes mellitus, post-gastric surgery, and disorders of idiopathic origin. ${ }^{10}$ The common causes of GP are as follows: neuropathic disorders including diabetes mellitus, post-vagotomy, scleroderma, and myopathic diseases. ${ }^{7}$ Other causes of GP include connective tissue diseases, neurological diseases such as Parkinson disease, eating disorders, metabolic or endocrine conditions including hypothyroidism, critical illness, and medications especially opiate narcotic analgesics and anticholinergic agents. GP is one of the common complications of diabetes mellitus. Moreover, delayed gastric emptying occurs in approximately $40 \%$ of patients with longstanding type 1 diabetes mellitus and approximately $20 \%$ of patients with type 2 diabetes mellitus. However, an underlying cause cannot be established in approximately $50 \%$ of patients classified as having idiopathic GP.

\section{Functional Dyspepsia}

The etiology of FD is diverse among patients. While FD can be attributed to genetic predisposition in some patients, a prior viral infection, stress, inflammation, surgery, trauma, or Helicobacter pylori infection can be another cause in other patients. Although no clear cause-effect relationship has been established, hormonal influences may affect symptoms in some patients with FD.

\section{Pathophysiology}

Abnormalities of the gastric sensorimotor function have been identified in both GP and FD and can overlap (Table 1). ${ }^{11}$ In addition to delayed gastric emptying, these abnormalities include impaired post-meal gastric accommodation, hypersensitivity to gastric distention, altered duodenal sensitivity to lipids or acids, abnormal intestinal motility, and central nervous system dysfunction. ${ }^{2}$

Table 1. Pathophysiology of Gastroparesis and Functional Dyspepsia

\begin{tabular}{|c|c|c|c|}
\hline \multirow[b]{2}{*}{ Pathophysiology } & \multirow[b]{2}{*}{$\begin{array}{l}\text { Gastro- } \\
\text { paresis }\end{array}$} & \multicolumn{2}{|c|}{$\begin{array}{l}\text { Functional } \\
\text { dyspepsia }\end{array}$} \\
\hline & & $\begin{array}{l}\text { Epigas- } \\
\text { tric pain } \\
\text { syndrome }\end{array}$ & $\begin{array}{c}\text { Post- } \\
\text { prandial } \\
\text { distress } \\
\text { syndrome }\end{array}$ \\
\hline Visceral hypersensitivity & $?$ & + & $?$ \\
\hline Delayed gastric emptying & + & & + \\
\hline Rapid gastric emptying & & + & \\
\hline Gastric dysrhythmias & + & & + \\
\hline Fundic accommodation & + & & + \\
\hline Weak antral pump & + & & \\
\hline Antroduodenal discoordination & + & & + \\
\hline $\begin{array}{l}\text { Duodenal neuromuscular } \\
\text { dysfunction }\end{array}$ & + & & + \\
\hline Duodenal eosinophilia & & + & + \\
\hline Abnormal duodenal feedback & + & & \\
\hline Sensitivity to acid, bile, and fats & & + & \\
\hline
\end{tabular}




\section{Gastroparesis}

Although the pathophysiology of GP has not been fully explained, known abnormalities include the dysfunction of several elements, such as autonomic (vagal) neuropathy, intrinsic neuropathy involving the excitatory and inhibitory intrinsic nerves or interstitial cells of Cajal (ICCs), disorders of both extrinsic and intrinsic neuropathy including diabetes mellitus and viral infection, and myopathic diseases. $^{7}$

ICCs are the most recognized cells that regulate smooth muscle contractility through slow wave progression. ICCs are being investigated across a multitude of pathology studies on motility. Therefore, it is becoming increasingly apparent how important ICCs are in the regulation of intestinal motility.

Examinations of histological changes in patients with GP specifically targeting ICCs have been increasingly performed. A decrease in the number of ICCs has been reported in patients with diabetic and idiopathic GP, possibly affecting close to one-third of the examined patients. Consistent with the recognized role of ICCs in gastric physiology, Lin et $\mathrm{al}^{12}$ demonstrated a correlation between low number of ICCs and more abnormalities in gastric electrical activity. However, this correlation has not been expanded beyond changes in gastric electrical phenomenon. Furthermore, ICC loss could not predict severity of symptom.

Intrinsic or enteric neural deficit can occur due to the inflammatory (eg, macrophage-induced) or degenerative (eg, due to reactive oxygen species) mechanisms in diabetic GP, which are similar to other diabetic neurologic complications, such as peripheral or autonomic neuropathy.

GP is also associated with fundic tone abnormalities, antroduodenal discoordination, weak antrum pump, gastric dysrhythmias, and abnormal duodenal feedback. ${ }^{13,14}$

\section{Functional Dyspepsia}

The pathogenesis of FD is currently attributed to a compound of upper gastrointestinal motility and visceral hypersensitivity disorders combined by the enteric nerve system. Pathophysiological abnormalities of FD include changes in the gastric emptying rate (either delayed or accelerated), impairment of gastric accommodation, gastric or duodenal hypersensitivity to certain nutrients found in food, and gastric or duodenal distension. ${ }^{15,16}$

Visceral hypersensitivity is considered an important phenomenon that can clarify many unexplained gastrointestinal symptoms., ${ }^{2,12}$ However, the mechanisms of visceral hypersensitivity and triggers of hypersensitivity remain under investigation. ${ }^{17}$ The issue of altered chemosensitivity in the gastrointestinal tract has been addressed in the literature. Capsaicin-sensitive afferent nerves are involved in the control of gastric and intestinal sensorimotor function, and the upregulation of capsaicin-sensitive transient receptor potential V1 channels is a potential mechanism underlying hypersensitivity. Hammer et $a^{18}$ reported that the FD patient group had significantly higher sensitivity to capsaicin than the healthy control groups. These findings support chemosensitivity as a factor of visceral hypersensitivity in FD.

Several studies have shown the role of psychosocial factors in the pathogenesis of visceral hypersensitivity. In a large cohort of patients with $\mathrm{FD}$, a history of abuse was associated with increased sensitivity to gastric distention, whereas no association with gastric emptying rate was mentioned. ${ }^{19}$ In another study, psychosocial factors such as depression, history of abuse, and somatization were the main determinants of symptom severity and weight loss associated with FD, and visceral hypersensitivity had a minimal effect. Motor dysfunction was not an independent determinant of symptom severity in this cohort. ${ }^{20}$

Several functional brain imaging studies have been performed in patients with FD to assess functional changes in the brain arising from controlled gastric distension. ${ }^{21}$ Despite the large diversity of results, the activation of homeostatic afferent brain circuits in FD patients has been reported in contrast to that in healthy controls. Alterations in attentional mechanisms, particularly increased threatrelated attention, associated with hypervigilance and future-directed symptom-related fears of sensations in the upper gastrointestinal tract have been demonstrated as important pathophysiological components of functional pain and anxiety disorders. ${ }^{22}$

The number of mast cells and eosinophils in the duodenal mucosa was found to be positively correlated with loss of mucosal integrity in $\mathrm{FD}^{23}$ A study from Japan confirmed that the number of eosinophils in the duodenum was higher in patients with FD and that intercellular distance correlated with postprandial fullness and early satiation. ${ }^{24} \mathrm{Du}$ et $\mathrm{al}^{25}$ used immunohistochemistry techniques to examine degranulation on biopsies of duodenal mucosa in 96 patients with FD and 24 controls. The eosinophil counts of both groups were similar, FD patients had a higher number of degranulated eosinophils in the duodenal mucosa; however, degranulated mast cells were not significantly different. The authors observed that the number of degranulated eosinophils positively correlated with postprandial fullness but inversely correlated with the frequency of epigastric pain. 


\section{Symptoms}

Pathophysiological results do not necessarily predict the symptoms of FD and GP, and investigators have questioned whether individual symptoms can accurately predict the underlying pathophysiology. ${ }^{1}$ Some symptoms common to both diseases, including epigastric fullness, nausea, and vomiting, have been associated with delayed gastric emptying. ${ }^{26}$

\section{Gastroparesis}

Patients with GP report identical symptoms of epigastric pain, postprandial fullness, nausea, and vomiting. Many reports describe the poor relationship between gastric emptying and symptoms; however, the responsiveness of both pathophysiology and symptoms to therapeutic interventions, especially when the intervention targets a specific mechanism, more convincingly supports the relationship between pathophysiology and symptoms. ${ }^{7,26}$

\section{Functional Dyspepsia}

FD patients with abnormal fundic accommodation usually complain of symptoms of early satiety, epigastric pain, or discomfort, and postprandial fullness and nausea, although these symptoms may not be any different from those in patients with normal accommodation.

In FD, the predominant sensation of early satiety has been proven to be closely associated with impaired accommodation, although it is also reported in $25 \%$ of patients with delayed gastric emptying. ${ }^{27}$ Nausea and vomiting, the cardinal symptoms of GP, develop in at least $20-50 \%$ of FD patients. ${ }^{28}$

\section{Diagnosis}

GP and FD overlap each other with respect to sensory dysfunction; however, tests for sensory abnormality are limited in clinical scenarios. Currently available functional test modalities merely check the motor function. Abnormality in gastric emptying time can be associated with global dysmotility, such as that affecting the small bowel and colon. ${ }^{29}$ Furthermore, there are no validated algorithms for the diagnosis of GP and FD. ${ }^{1}$

It is critical to clearly distinguish patients with FD from those with GP and to better understand the relationship among alterations in specific symptoms, gastric emptying, and altered peripheral and central sensory responses to gastric stimuli. Furthermore, differential diagnosis of GP excludes other possible causes, such as peptic ulcer disease, gastric outlet obstruction, neoplasm, and small bowel obstruction. Various diagnostic modalities are used to differentiate these pathologies.

Differential diagnosis consists of 2 steps. ${ }^{7}$ First, mechanical obstruction should be excluded by imaging techniques (preferentially upper gastrointestinal endoscopy and computed tomographic or magnetic resonance enterography). Second, motility abnormality should be assessed using various tests, including gastric emptying test and manometry.

\section{Gastroparesis}

Although various methods objectively measure gastric emptying, the 4-hour solid phase scintigraphic emptying scan is the most frequently conducted. ${ }^{14}$ In general, gastric retention of $>10 \%$ at 4 hours is considered delayed gastric emptying of solids. ${ }^{8}$ However, symptoms poorly differentiate categories of GP or status of gastric emptying. ${ }^{2}$ If delayed gastric emptying is confirmed, the cause of symptoms should be evaluated by reviewing clinical features and possibly conducting additional tests. A particularly confusing problem that has not yet been resolved is how to distinguish GP from FD. The fundamental problem is that slow gastric emptying occurs in $25 \%$ of patients with $\mathrm{FD}$; however, there is no clear associated symptom complex. If GP is more strictly defined as comprising a greater gastric emptying delay (potentially $>60 \%$ of meal retained in the stomach after 4 hours), then vomiting and weight loss may be more predictably associated with this GP, even if its incidence would decrease. ${ }^{30}$

The gastric emptying breath test using $\mathrm{C}^{13}$ is employed to assess gastric function. ${ }^{31}$ Numerous studies using simultaneous scintigraphy and breath test have validated the ability of the breath test to quantify gastric emptying. ${ }^{32}$ It should be noted that significant hepatic and pulmonary disease can affect $\mathrm{CO}_{2}$ metabolism and test results.

Another diagnostic test is the wireless motility capsule (WMC), which measures small bowel and colonic transit, pressure, temperature, and $\mathrm{pH}$, as well as gastric motility. Using a 5-hour cutoff for gastric emptying, the capsule could differentiate normal gastric emptying from delayed gastric emptying with a sensitivity and specificity of $87 \%$ and $92 \%$, respectively. ${ }^{3}$ A recent report indicated that the small bowel fed response was observed in healthy subjects and those with chronic constipation using WMC but was blunted in $\mathrm{GP}^{33}$ Abnormal contraction may suggest severe myopathy. In a study comparing WMC and scintigraphy in 61 patients with GP, the correlation between WMC and scintigraphy was reasonable $(73 \%)$ at 4 huors. ${ }^{34}$ Therefore, all of these 3 tests are reasonable mo- 
Table 2. Comparison of Methods Used to Assess Gastric Emptying

\begin{tabular}{lcll}
\hline \multicolumn{1}{c}{ Method } & $\begin{array}{c}\text { Assessment } \\
\text { of antral } \\
\text { contractility }\end{array}$ & $\begin{array}{c}\text { Assessment of } \\
\text { small bowel and } \\
\text { colonic transit }\end{array}$ & $\begin{array}{c}\text { Radiation } \\
\text { exposure }\end{array}$ \\
\hline Scintigraphy & Feasible & Feasible & Yes \\
Breath test & No & Limited or poor & No \\
Wireless motility capsule & Yes & Yes & No \\
\hline
\end{tabular}

dalities for the estimation of GP (Table 2).

\section{Functional Dyspepsia}

Several functional tests can identify abnormalities in motility. Antroduodenal manometry aids patients with gastric dysmotility and helps differentiate the neuropathic and myopathic origins of the disease. ${ }^{35}$ This test determines the presence of the migrating motor complex. Normal-amplitude uncoordinated contractions are detected in patients with neuropathies, whereas low-amplitude or completely absent contractions suggest a myopathic origin. In patients with type 1 or type 2 diabetes mellitus, phase III of the migrating motor complex is typically abolished. Unfortunately, this test is limited to few secondary centers and is poorly tolerated by patients.

Although gastric barostat study is a standard assessment method for gastric accommodation, it is invasive and poorly tolerated to be performed in routine clinical practice. Nevertheless, the Leuven group reported on their experience with a large cohort of patients $(n=414)$ undergoing gastric barostat measurements. The authors reported that $98 \%$ of scheduled gastric barostat studies were well tolerated and that $94 \%$ were technically appropriate. ${ }^{17}$

Newly developed techniques such as single-photon emission computed tomography, 3-dimensional ultrasonography, and magnetic resonance imaging can measure gastric volumes and are promising alternatives for the noninvasive assessment of gastric accommodation. 36,37

A less intrusive approach is the slow nutrient drinking test which approximates gastric accommodation. ${ }^{38}$ Kindt et a ${ }^{39}$ evaluated the reproducibility of the slow nutrient drinking test and its relationship with demographic, symptomatic, and pathophysiological variables in an analysis involving 78 secondary care patients with dyspepsia and 34 healthy controls. The maximum ingested amount was significantly lower in patients with dyspepsia and depended on age, sex, and baseline FD symptom score. The reproducibility of the drinking test was excellent, identifying its possible role as an attractive noninvasive tool for diagnosing impaired accommodation and for assessing treatment responsiveness.

\section{Treatment}

As the symptoms of gastric sensorimotor disorders do not discriminate FD from idiopathic GP definitively, patients with dyspepsia should be treated based on their predominant symptoms, regardless of the delay in gastric emptying. ${ }^{1}$ Moreover, the treatment for both disorders can be complicated, particularly in severe cases, because patients typically present with multiple morbid symptoms. ${ }^{15}$ Current treatment options for these 2 disorders are summarized in Table 3.

\section{Gastroparesis}

Evaluation and correction of any underlying conditions that may cause gastric dysmotility should form the cornerstone of the beginning of a therapeutic plan for GP. Restoration of hydration, electrolyte balance, and nutrition and pharmacological treatment with prokinetics and antiemetics form the mainstay of treatment., For more severe cases, the practitioner may consider nonpharmacological therapy, such as enteral feeding, percutaneous gastrostomy for gastric drainage, or gastric electrical stimulation. ${ }^{13}$

Prokinetic agents are drugs that strengthen coordinated gastrointestinal motility and transit of content in the gastrointestinal tract, mainly through amplifying and coordinating gastrointestinal muscle contractions. In general, myopathic GP may not satisfactorily respond to prokinetic agents.

Antiemetic agents act chiefly by either central or peripheral blockade of different neurotransmitters involved in nausea-promoting pathways. These agents are typical in both acute and long-term management. ${ }^{40}$

Erythromycin is a motilin receptor agonist involved in 2 different pathways by activating motilin receptors on the cholinergic neurons and muscles. ${ }^{3}$ Erythromycin is administered in low-dose (eg, 50-100 mg, $1 \mathrm{mg} / \mathrm{kg}$ ) liquid formulation; at higher doses such as when used as an antibiotic, erythromycin can cause nausea, vomiting, and abdominal pain as its side effects. Unfortunately, erythromycin is associated with several adverse events, such as tachyphylaxis, which can be addressed with short drug holiday.

Low doses of ghrelin accelerate gastric emptying and improve symptoms. ${ }^{41,42}$ Contraction of the proximal part of the stomach possibly aggravates postprandial symptoms. Relamorelin, an injectable ghrelin receptor agonist, significantly enhances gastric emptying in diabetic GP patients with vomiting.

Serotonin (5-Hydroxytryptamine $4\left[5-\mathrm{HT}_{4}\right]$ ) receptor agonists such as prucalopride and velusetrag accelerate gastric empty- 
Table 3. Summary of Treatment Options for Gastroparesis and Functional Dyspepsia

\begin{tabular}{|c|c|c|}
\hline Treatment & Gastroparesis & Functional dyspepsia \\
\hline Dietary modification & $\begin{array}{l}\text { Frequent low-fat, low-fiber meals and nourishing } \\
\text { liquids }\end{array}$ & $\begin{array}{l}\text { Small, frequent meals } \\
\text { Reduction in dietary lipid intake } \\
\text { Elimination of problematic proteins }\end{array}$ \\
\hline Pharmacological therapy & $\begin{array}{l}\text { Prokinetic agents } \\
\text { Anti-emetic agents } \\
\text { Erythromycin } \\
\text { Ghrelin receptor agonist (relamorelin) } \\
5-\mathrm{HT}_{4} \text { receptor agonist (prucalopride, velusetrag) }\end{array}$ & $\begin{array}{l}\text { Prokinetic agents } \\
\text { Acid suppression therapy (histamine } \mathrm{H} 2 \text { receptor an- } \\
\text { tagonist, proton pump inhibitors) } \\
\text { Buspirone } \\
\text { Serotonergic agents } \\
\text { Aticoamide } \\
\text { Helicobacter pylori eradication } \\
\text { Antidepressant therapy (amitriptyline, tricyclic antide- } \\
\text { pressant) }\end{array}$ \\
\hline Interventional therapy & $\begin{array}{l}\text { Gastric electrical stimulation } \\
\text { Gastrostomy/jejunostomy } \\
\text { Surgical pyloroplasty } \\
\text { Gastric peroral endoscopic myotomy } \\
\text { Intrapyloric botulinum toxin injection }\end{array}$ & \\
\hline $\begin{array}{l}\text { Complementary and alternative } \\
\text { options }\end{array}$ & $\begin{array}{l}\text { Acupuncture } \\
\text { Herbal preparations }\end{array}$ & $\begin{array}{l}\text { Cognitive-behavioral therapy/hypnotherapy } \\
\text { Acupuncture } \\
\text { Herbal preparations }\end{array}$ \\
\hline
\end{tabular}

5- $\mathrm{HT}_{4}, 5$-hydroxytryptamine 4 receptor.

ing and relieve symptoms in idiopathic GP. Previous studies have reported the dose-dependent selectivity of $5-\mathrm{HT}_{4}$ receptors over the human ether-a-go-go-related gene channel and other receptors. ${ }^{43-46}$

Nonpharmacological treatment is recommended for severe cases of GP, because drug therapy alone is not effective. Gastric electrical stimulation is a potential therapeutic option for intractable symptoms of GP and is considered an alternative treatment for patients with refractory symptoms such as nausea and vomiting. Symptom severity and gastric emptying have a limited effect in patients with diabetic $\mathrm{GP}^{47}$ However, some studies did not show its clinical efficacy in reducing symptoms in patients with GP, limiting its use.

Endoscopic and surgical treatment modalities are available for eligible patients with recalcitrant GP; however, the use of interventional treatment options for GP is limited by modest clinical evidence. Generally, they should not be recommended for FD.

Gastrostomy and/or jejunostomy could be performed for symptomatic relief and enteral feeding beyond the delayed stomach. Because of poor outcomes, venting gastrostomy is not usually recommended because of the potential for loss of gastric accommodation with chronic venting. Gastrectomy is an option for patients with postsurgical GP who remain severely symptomatic and do not respond successfully to medical therapy; however, the evidence is only anecdotal, and surgery will not relieve chronic pain. ${ }^{7}$ Surgical pyloroplasty or gastrojejunostomy should only be performed rarely in carefully selected patients.

Gastric peroral endoscopic myotomy for refractory GP is an extension of peroral endoscopic myotomy, a well studied treatment option for achalasia. This procedure shows promising clinical outcomes and potential as a new therapy, despite need for larger shamcontrolled studies and additional research to identify patients who may significantly benefit from this procedure. ${ }^{14}$

The assumption that pylorospasm may recurrently impede gastric emptying has increased the therapeutic interest in pyloric botulinum toxin injections. Botulinum toxin endoscopically delivered to the pylorus had been shown to improve mean symptom scores and health-related quality of life in subjects with type 1 diabetes mellitus; however, patients with GP of mixed etiology experienced no significant benefit. ${ }^{48}$ Nonetheless, sham-controlled trials on pyloric botulinum toxin injections failed to report any significant difference.

Acupuncture, associated with a reduction in symptoms and improvement in gastric emptying, can also be considered an alternative therapy. Although further testing is needed, it appears to have a short-term effect on diabetic $\mathrm{GP}^{49,50}$ 


\section{Functional Dyspepsia}

FD involves complex pathophysiological mechanisms including visceral hypersensitivity, impaired gastric accommodation, delayed gastric emptying, $H$. pylori infection, psychosocial disorders, and even unhealthy lifestyle.

The primary treatment for FD has been aimed at gastric acid secretion and impaired gut motility. Therefore, prokinetics and acidinhibitory drugs are the mainstay of treatment for FD. According to a recent network meta-analysis, metoclopramide, trimebutine, mosapride, and domperidone were more effective in treating FD than itopride or acotiamide. ${ }^{51}$ However, considering the adverse events related to medications, short-term or alternative use of these drugs could be recommended for the symptomatic relief of FD.

Acid suppression therapy with $\mathrm{H}_{2}$ receptor antagonist or proton pump inhibitor is effective in patients with FD. Numerous clinical trials on proton pump inhibitors demonstrate their favorable effect in $\mathrm{FD}$ patients compared to subjects receiving placebos. ${ }^{52}$ Acid secretion inhibitors are recommended for patients with EPS, whereas prokinetic agents such as mosapride and acotiamide are recommended for those with PDS.

Buspirone, a $5-\mathrm{HT}_{1 \mathrm{~A}}$ receptor agonist, was the first drug to enhance fundic relaxation and to relieve reduced gastric accommodation. ${ }^{53}$ Furthermore, buspirone relieves the symptoms of FD. ${ }^{54}$

Serotonin $5-\mathrm{HT}_{3}$ receptor antagonists, such as ondansetron and granisetron, act primarily through central and peripheral $5-\mathrm{HT}_{3}$ receptor blockade.

Acotiamide, a muscarinic $\mathrm{M}_{1} / \mathrm{M}_{2}$ receptor antagonist that enhances acetylcholine release, may improve gastric accommodation and dyspeptic symptoms. ${ }^{55}$

Although the role of $H$. pylori infection in FD has not been fully elucidated, the main mechanisms of symptom development in $H$. pylori-associated FD were altered gastrointestinal motility and mucosal inflammation. However, therapeutic benefits and symptomatic improvements following $H$. pylori eradication in patients with FD are not consistent. Nevertheless, $H$. pylori eradication is an important treatment option because of its curative potential.

Psychosocial factors have been proposed as an important element in the pathophysiology of FD. A recent systematic review showed that psychotropic agents with anxiolytic or antidepressant actions were effective in alleviating FD symptoms. ${ }^{56}$ Antidepressant therapy with amitriptyline is useful for FD associated with normal gastric emptying, but not in FD associated with delayed gastric emptying. ${ }^{57} \mathrm{~A}$ meta-analysis of psychotropic agents showed that tricyclic antidepressants showed significant effects compared to the placebo but the risk of adverse events remained. There was no benefit observed over the placebo with selective serotonin reuptake inhibitors or selective norepinephrine reuptake inhibitors.

As a nonpharmacological approach, extensive interventions such as psychotherapy or cognitive therapy may be effective in reducing the symptoms of patients with FD. An Iranian quasi-experimental study showed that cognitive-behavioral stress management strategies were effective in reducing the symptoms of patients with FD. Furthermore, combining psychotherapy and standard medical therapy may improve the short-term outcomes in patients with FD. ${ }^{58,59}$ Brief psychodynamic therapy may improve symptoms, mature defenses, and alexithymia scores in these patients. ${ }^{60}$

Hypnotherapy has been performed as treatment for FD. Hypnotherapy, which is delivered as a structured, multi-session, focused intervention, has been widely used to treat irritable bowel syndrome. However, its therapeutic efficacy in FD remains limited. Although Chiarioni et al. reported significant improvement in symptoms by hypnosis in patients with FD, they observed no correlation with gastric emptying time.

Acupuncture is also effective for FD. While most studies have not been rigorously examined, short-term treatment with acupuncture appears to be effective in reducing symptoms in FD patients. ${ }^{61,62}$

Herbal medicines with mechanisms of action that have not been clearly identified, several herbal supplements such as rikkunshito (a Japanese herbal medicine that improves gastric emptying), and STW5 (also known as iberogast) were superior to placebo in relation to symptomatic improvement. Overall, convincing data supporting the use of any herbal therapies as treatment for FD are lacking.

\section{Conclusions}

This review addressed important aspects in the present understanding about the pathophysiology, symptom, diagnosis, and treatment of GP and FD. These disorders share a similar pathogenesis in some cases, and it might be artificial to separate them from each other. Current treatment options for GP and FD are limited; however, it is expected that this situation will substantially improve as the understanding of the pathophysiology of these 2 disorders broadens. Furthermore, a combination of approaches (ie, basic research, clinical investigation, and controlled clinical trials) is required to improve patient care in these conditions. 


\section{Financial support: None.}

\section{Conflicts of interest: None.}

Author contributions: Beom Jin Kim drafted and revised the manuscript; and Braden Kuo designed and supervised the manuscript.

\section{References}

1. Lacy BE. Functional dyspepsia and gastroparesis: one disease or two? Am J Gastroenterol 2012;107:1615-1620.

2. Tack J. Gastric motor and sensory function. Curr Opin Gastroenterol 2009;25:557-565.

3. Parkman HP, Camilleri M, Farrugia G, et al. Gastroparesis and functional dyspepsia: excerpts from the AGA/ANMS meeting. Neurogastroenterol Motil 2010;22:113-133.

4. Parkman HP. Idiopathic gastroparesis. Gastroenterol Clin North Am 2015;44:59-68.

5. Arthur LE, Slattery L, Richardson W. Tailored approach to gastroparesis significantly improves symptoms. Surg Endosc 2018;32:977-982.

6. Stanghellini V, Chan FK, Hasler WL, et al. Gastroduodenal disorders. Gastroenterology 2016;150:1380-1392.

7. Camilleri M. Functional dyspepsia and gastroparesis. Dig Dis 2016;34:491-499

8. Parkman HP, Hallinan EK, Hasler WL, et al. Early satiety and postprandial fullness in gastroparesis correlate with gastroparesis severity, gastric emptying, and water load testing. Neurogastroenterol Motil Published Online First: 25 Oct 2016. doi: 10.1111/nmo.12981.

9. Vanheel H, Carbone F, Valvekens L, et al. Pathophysiological abnormalities in functional dyspepsia subgroups according to the Rome III criteria. Am J Gastroenterol 2017;112:132-140.

10. Liu N, Abell T. Gastroparesis updates on pathogenesis and management. Gut Liver 2017;11:579-589.

11. Kindt S, Dubois D, Van Oudenhove L, et al. Relationship between symptom pattern, assessed by the PAGI-SYM questionnaire, and gastric sensorimotor dysfunction in functional dyspepsia. Neurogastroenterol Motil 2009;21:1183-e105.

12. Lin Z, Sarosiek I, Forster J, Damjanov I, Hou Q, McCallum RW. Association of the status of interstitial cells of Cajal and electrogastrogram parameters, gastric emptying and symptoms in patients with gastroparesis. Neurogastroenterol Motil 2010;22:56-61, e10.

13. Camilleri M, Parkman HP, Shafi MA, Abell TL, Gerson L; American College of G. Clinical guideline: management of gastroparesis. Am J Gastroenterol 2013;108:18-37.

14. Navas CM, Patel NK, Lacy BE. Gastroparesis: medical and therapeutic advances. Dig Dis Sci 2017;62:2231-2240.

15. Stein B, Everhart KK, Lacy BE. Treatment of functional dyspepsia and gastroparesis. Curr Treat Options Gastroenterol 2014;12:385-397.

16. Mimidis K, Tack J. Pathogenesis of dyspepsia. Dig Dis 2008;26:194202.

17. Kindt S, Tack J. Impaired gastric accommodation and its role in dyspep- sia. Gut 2006;55:1685-1691.

18. Hammer J, Führer M, Pipal L, Matiasek J. Hypersensitivity for capsaicin in patients with functional dyspepsia. Neurogastroenterol Motil 2008;20:125-133.

19. Geeraerts B, Van Oudenhove L, Fischler B, et al. Influence of abuse history on gastric sensorimotor function in functional dyspepsia. Neurogastroenterol Motil 2009;21:33-41.

20. Van Oudenhove L, Vandenberghe J, Geeraerts B, et al. Determinants of symptoms in functional dyspepsia: gastric sensorimotor function, psychosocial factors or somatisation? Gut 2008;57:1666-1673.

21. Mayer EA, Aziz Q, Coen S, et al. Brain imaging approaches to the study of functional GI disorders: a Rome working team report. Neurogastroenterol Motil 2009;21:579-596.

22. Mayer EA, Bradesi S, Chang L, Spiegel BM, Bueller JA, Naliboff BD. Functional GI disorders: from animal models to drug development. Gut 2008;57:384-404

23. Vanheel H, Vicario M, Vanuytsel T, et al. Impaired duodenal mucosal integrity and low-grade inflammation in functional dyspepsia. Gut 2014;63:262-271.

24. Tanaka F, Tominaga K, Fujikawa Y, et al. Concentration of glial cell linederived neurotrophic factor positively correlates with symptoms in functional dyspepsia. Dig Dis Sci 2016;61:3478-3485.

25. Du L, Shen J, Kim JJ, Yu Y, Ma L, Dai N. Increased duodenal eosinophil degranulation in patients with functional dyspepsia: a prospective study. Sci Rep 2016;6:34305.

26. Sarnelli G, Caenepeel P, Geypens B, Janssens J, Tack J. Symptoms associated with impaired gastric emptying of solids and liquids in functional dyspepsia. Am J Gastroenterol 2003;98:783-788.

27. Karamanolis G, Caenepeel P,, Arts J, Tack J. Determinants of symptom pattern in idiopathic severely delayed gastric emptying: gastric emptying rate or proximal stomach dysfunction? Gut 2007;56:29-36.

28. Bisschops R, Karamanolis G, Arts J, et al. Relationship between symptoms and ingestion of a meal in functional dyspepsia. Gut 2008;57:14951503.

29. Gwee KA, Chua AS. Functional dyspepsia and irritable bowel syndrome, are they different entities and does it matter? World J Gastroenterol 2006;12:2708-2712.

30. Harrell SP, Studts JL, Dryden GW, Eversmann J, Cai L, Wo JM. A novel classification scheme for gastroparesis based on predominantsymptom presentation. J Clin Gastroenterol. 2008;42:455-459.

31. Viramontes BE, Kim DY, Camilleri M, et al. Validation of a stable isotope gastric emptying test for normal, accelerated or delayed gastric emptying. Neurogastroenterol Motil 2001;13:567-574.

32. Parkman HP, Camilleri M, Farrugia G, et al. Gastroparesis and functional dyspepsia: excerpts from the AGA/ANMS meeting. Neurogastroenterol Motil. 2010;22:113-133.

33. Surjanhata B, Brun R, Wilding G, Semler J, Kuo B. Small bowel fed response as measured by wireless motility capsule: comparative analysis in healthy, gastroparetic, and constipated subjects. Neurogastroenterol Motil 2018;30:e13268.

34. Kuo B, McCallum RW, Koch KL, et al. Comparison of gastric emptying of a nondigestible capsule to a radio-labelled meal in healthy and gastro- 
paretic subjects. Aliment Pharmacol Ther 2008;27:186-196.

35. Brun R, Kuo B. Functional dyspepsia. Therap Adv Gastroenterol 2010;3:145-164

36. Vijayvargiya P, Camilleri M, Shin A, Breen M, Burton D. Simplifying the measurement of gastric accommodation using SPECT. Neurogastroenterol Motil 2013;25:542-546.

37. Ang D. Measurement of gastric accommodation: a reappraisal of conventional and emerging modalities. Neurogastroenterol Motil 2011;23:287291.

38. Tutuian R, Vos R, Karamanolis G, Tack J. An audit of technical pitfalls of gastric barostat testing in dyspepsia. Neurogastroenterol Motil 2008;20:113-118.

39. Kindt S, Coulie B, Wajs E, Janssens J, Tack J. Reproducibility and symptomatic predictors of a slow nutrient drinking test in health and in functional dyspepsia. Neurogastroenterol Motil 2008;20:320-329.

40. Acosta A, Camilleri M. Prokinetics in gastroparesis. Gastroenterol Clin North Am 2015;44:97-111.

41. Murray CD, Martin NM, Patterson M, et al. Ghrelin enhances gastric emptying in diabetic gastroparesis: a double blind, placebo controlled, crossover study. Gut 2005;54:1693-1698.

42. Tack J, Depoortere I, Bisschops R, Verbeke K, Janssens J, Peeters T. Influence of ghrelin on gastric emptying and meal-related symptoms in idiopathic gastroparesis. Aliment Pharmacol Ther 2005;22:847-853.

43. Bouras EP, Camilleri M, Burton DD, Thomforde G, McKinzie S, Zinsmeister AR. Prucalopride accelerates gastrointestinal and colonic transit in patients with constipation without a rectal evacuation disorder. Gastroenterology 2001;120:354-360.

44. De Maeyer JH, Lefebvre RA, Schuurkes JA. 5- $\mathrm{HT}_{4}$ receptor agonists: similar but not the same. Neurogastroenterol Motil 2008;20:99-112.

45. Smith JA, Beattie DT, Marquess D, Shaw JP, Vickery RG, Humphrey PP. The in vitro pharmacological profile of TD-5108, a selective 5- $\mathrm{HT}_{4}$ receptor agonist with high intrinsic activity. Naunyn Schmiedebergs Arch Pharmacol 2008;378:125-137.

46. Manabe N, Wong BS, Camilleri M. New-generation 5-HT 4 receptor agonists: potential for treatment of gastrointestinal motility disorders. Expert Opin Investig Drugs 2010;19:765-775.

47. Lahr CJ, Griffith J, Subramony C, et al. Gastric electrical stimulation for abdominal pain in patients with symptoms of gastroparesis. Am Surg 2013;79:457-464.

48. Lacy BE, Crowell MD, Schettler-Duncan A, Mathis C, Pasricha PJ. The treatment of diabetic gastroparesis with botulinum toxin injection of the pylorus. Diabetes Care 2004;27:2341-2347.

49. Li G, Huang C, Zhang X, et al. The short-term effects of acupuncture on patients with diabetic gastroparesis: a randomised crossover study. Acupunct Med 2015;33:204-209.
50. Danielli Miller N, Schiff E, Ben-Arye E, et al. Benefits of acupunctureww for diabetic gastroparesis: a comparative preliminary study. Acupunct Med 2014;32:139-145.

51. Yang YJ, Bang CS, Baik GH, et al. Prokinetics for the treatment of functional dyspepsia: bayesian network meta-analysis. BMC Gastroenterol 2017;17:83.

52. Madisch A, Andresen V, Enck P, Labenz J, Frieling T, Schemann M. The diagnosis and treatment of functional dyspepsia. Dtsch Arztebl Int 2018;115:222-232.

53. Van Oudenhove L, Kindt S, Vos R, Coulie B, Tack J. Influence of buspirone on gastric sensorimotor function in man. Aliment Pharmacol Ther 2008;28:1326-1333.

54. Tack J, Janssen P, Masaoka T, Farré R, Van Oudenhove L. Efficacy of buspirone, a fundus-relaxing drug, in patients with functional dyspepsia. Clin Gastroenterol Hepatol 2012;10:1239-1245.

55. Seto K, Sasaki T, Katsunuma K, Kobayashi N, Tanaka K, Tack J. Acotiamide hydrochloride (Z-338), a novel prokinetic agent, restores delayed gastric emptying and feeding inhibition induced by restraint stress in rats. Neurogastroenterol Motil 2008;20:1051-1059.

56. Hojo M, Nagahara A, Asaoka D, et al. A systematic review of the effectiveness of antianxiety and antidepressive agents for functional dyspepsia. Intern Med 2017;56:3127-3133.

57. Lacy BE, Saito YA, Camilleri M, et al. Effects of antidepressants on gastric function in patients with functional dyspepsia. Am J Gastroenterol 2018;113:216-224.

58. Orive M, Barrio I, Orive VM, et al. A randomized controlled trial of a 10 week group psychotherapeutic treatment added to standard medical treatment in patients with functional dyspepsia. J Psychosom Res 2015;78:563-568.

59. Haag S, Senf W, Tagay S, et al. Is there a benefit from intensified medi$\mathrm{cal}$ and psychological interventions in patients with functional dyspepsia not responding to conventional therapy? Alimentary Pharmacology \& Therapeutics 2007;25:973-986.

60. Faramarzi M, Azadfallah P, Book HE, Tabatabaei KR, Taheri H, Shokri-shirvani J. A randomized controlled trial of brief psychoanalytic psychotherapy in patients with functional dyspepsia. Asian J Psychiatr 2013;6:228-234.

61. Ko SJ, Kuo B, Kim SK, et al. Individualized acupuncture for symptom relief in functional dyspepsia: a randomized controlled trial. J Altern Complement Med 2016;22:997-1006.

62. Pang B, Jiang T, Du YH, et al. Acupuncture for functional dyspepsia: what strength does it have? a systematic review and meta-analysis of randomized controlled trials. Evid Based Complement Alternat Med. 2016;2016:3862916. 